\title{
Numerical Investigation of the Unsteady Flows in Hydropower Plants
}

\author{
Roozbeh Aghamagidi $^{1 \times \bowtie}$, Mohammad Emami ${ }^{2}$, Dariush Firooznia ${ }^{3}$ \\ ${ }^{1}$ Professor Assistant, Civil Department, Islamic Azad University, Sepidan Branch, Sepidan, Iran \\ ${ }^{2}$ Faculty of Engineering, Islamic Azad University, ShahreKord Branch, Iran \\ 3Department of Maritime Engineering, Amirkabir University, Tehran, Iran \\ ${ }^{8}$ Corresponding author’s Email: roozbeh 1381@yahoo.com
}

\begin{abstract}
One of the most important hazards that threatens the stability of power plant buildings is the phenomenon of water hammer, which can occur in the Penstock pipe of a turbine due to the rapid opening and closing of a valve. Fluid Descriptive Equations in this situation, there are two hyperbolic partial nonlinear partial differential equations that are very difficult and complex to solve analytically and are possible only for very simple conditions. In this study, by examining the two numerical methods of characteristic lines and implicit finite difference with Verwy \& Yu schema, which are widely used in the analysis of instabilities, their disadvantages and advantages are clearly clarified and a suitable comparison basis for use. They should be provided in different conditions in hydropower plant. The results of the characteristic method in terms of maximum and minimum pressure show more and less values than the implicit finite difference method. In the characteristic method, perturbations and fast wave fronts are presented with more accuracy than the implicit finite difference method. At points near the upstream, downstream and middle boundaries, the accuracy of the characteristic method in presenting pressure and flow fluctuations is higher than the implicit finite difference method. In the characteristic method, it is recommended not to use certain time steps and try as much as possible avoid interpolation by selecting the appropriate time step. The results of examining the amount of changes in coefficient of friction in both methods show that it is not correct to take its value constant (proportional to the value obtained in stable conditions) and coefficient of friction should be calculated in proportion to changes in velocity at different times and used in the governing equation.
\end{abstract}

Keywords: Hydraulic Flow, Hydroelectric Power Plant, Water Hammer Phenomenon

\section{INTRODUCTION}

Water hammer (WH) is a phenomenon that happens in the under pressure pipeline and is based on the rules of the flow rate changes or the flow velocity changes and time or space condition of the fluid motion. Water hammer phenomenon (WHP) that is caused by rapid, transient and damped waves makes various dangerous in some of the under-pressure hydraulic systems such as, water pipeline, oil or distribution networks pipelines and water pipes leading to turbines. Sometimes there is a dire result due to RIP Such as, breaking in distribution and transmission pipeline system, failure in valves, control valves and pumps. In general, it is most important from aspect of practical and economical the analysing of these flows. There are many studies in this subject. Driels (1975), proposed a new method in which the pressure was reduced to a constant value by using a pressure relief valve and the minimum pressure remains in all points. Shimada and Okushima. (1984), investigated the effects of closing valve on creating RIP by characteristic lines. Chaudhry (1979) presented two difference diagram in frictionless and friction conditions for Lagrange expansion to analyse of the compressible and non-compressible flow fluid as well as the concept of velocity potential. Ghidaoui and Kolyshkin (2001), presented a step-by-step computational method to determine the changes in water turbine velocity that occurs due to changes in load. They considered the RI pressures, changing in turbine efficiency due to change in valve opening rate as well as uniform and non-uniform valve movements. Bergant et al. (2001), incorporated two unsteady friction models proposed by Zielke (1968) and Brunone et al (1991) into MOC water hammer analysis.

Ghidaoui et al. (2002), implemented and analysed the two layer and the five-layer eddy viscosity models of water hammer. A dimensionless parameter i.e., the ratio of the time scale of the radial diffusion of shear to the time scale of wave propagation has been developed for assessing the accuracy of the assumption of flow axisymmetric in both the models of water hammer.

Zhao and Ghidaoui (2003), have solved a quasi-two dimensional model for turbulent flow in water hammer. They have considered turbulent shear stress as resistance instead of friction factor. Zhao and Ghidaoui (2004), 
applied first - and second-order Godunov-type schemes for water hammer problems. Numerical tests showed that the first -order Godunov gives the same results to the MOC with space-line interpolation. Mimi and Kumar (2006), showed that at the performance of numerical methods, friction errors grow in unsteady flows, which are estimated in small pipeline networks for fixed coordinate plates, which is so the characteristic lines without interpolation.

Tijsseling and Bergant (2007), proposed a method based on the MOC, but a numerical grid is not required. The water hammer equations without friction have been solved exactly for the time -dependent boundary and constant (steady state) initial conditions with this method. Their method was the simplicity of the algorithm (recursion) and the fast and accurate (exact) calculation of transient events but calculation time strongly increased the events of longer duration. Kwon and Lee (2008), simulated transient flow in a pipe involving backflow preventers using both experimental and three different numerical models of the method of characteristics model (MOC), the asymmetrical model and the implicit scheme model. The results of different computer models agree well with the experimental data.

Hou. et al. (2012), simulated water hammer with the corrective smoothed particle method (CSPM). The CSPM results are in good agreement with conventional MOC solutions. This paper aims at the investigation of four explicit finite difference solutions of water hammer and their comparison with the largely established solutions of MOC and Godunov. (2) (PDF) Water hammer simulation by explicit central finite difference methods in staggered grids. Available from:

It is necessary to have access to the distribution of head and flow rate in different operating conditions to design and operate any pipeline. For this reason, many of researchers have simulated transient flows in water pipelines by using variety of methods. Among the existing methods, numerical methods have acceptable accuracy compared to other methods. In the numerical methods, the two methods of characteristic lines and finite difference have many applications in solving related equations. Therefore, the study of these two methods in analysing the RIP is importance that has been tried to be investigate in this study.

According to the studies the water velocity in penstock pipes is over $10 \mathrm{~m} / \mathrm{s}$. then the line pressure due to high velocity causes problems into this pipes. For controlling of the unsteady flow it can be used the finite element and characteristic lines methods. In this study we investigated a simple method for prediction amount of the flow before arriving to the hydropower plants by characteristic lines method.

\section{MATERIAL AND METHODS}

To solve the RIP equations witch are in part of the hyperbolic partial differential equations, it is necessary to use initial and boundary condition for analysing. To define the initial condition at first we analysed a numerical model by using a stable hydraulic condition analysis software to determine the main flow characteristics including velocity and pressure in the system. In this study the software is Epanet. Then the output results imported to Mikenet and Hammer models. It is same preparing the initial conditions for two models. After transferring the results of stable numerical hydraulic to the models it is begun according to the model the definition of initial conditions. It is necessary to pay attention that the initial condition have to be same in both computer models. It should be take care if we use difference methods in the definition above conditions because in case of any faults in the implementation the boundary conditions the results will be difference in terms of hydraulically. The boundary condition must be defined at critical points such as beginning and ending of the system points which is changed in any examples according to what we want to be done. In all of the examples in this study it mostly has been used of the same boundary conditions such as the tank with constant head at the upstream and a flow control valve boundary condition at the downstream. The next step is to determine the speed of wave transmission in the system when the analysis is based on the theory of elasticity. The wave speed can be calculated by different method in channels with various materials and shapes. In the examples it has been used from the thick duct formula. After determining the wave velocity, it should be determined the time interval for analysing the system. Since we use two explicit and implicit methods in solving the governing equations interval time should be choice that the Courant number to be less than one $(\mathrm{Cr}<=1)$ due to prevent numerical instability in the models. Also, the time required for each analysis can be determined according to how the boundaries change, which is approximately defined by (Eq.1).

$(20 \mathrm{~L} / \mathrm{a})$

For most engineering applications water hammer equations are appropriate (Chaudhry, 1979). 


$$
\begin{gathered}
\frac{\partial H}{\partial t}+\frac{a^{2}}{g A} \frac{\partial Q}{\partial x}=0 \\
\frac{\partial \mathrm{H}}{\partial \mathrm{x}}+\frac{1}{\mathrm{gA}} \frac{\partial \mathrm{Q}}{\mathrm{Qt}}+\frac{\mathrm{fQ}|\mathrm{Q}|}{2 \mathrm{gDA}^{2}}=0
\end{gathered}
$$

\section{RESULTS}

The purpose of this study is to investigate the hydraulic of damping flows using two methods of characteristic lines and implicit finite difference which we used several examples of difference boundary and initial conditions to determine the weakness and strengths points of two methods. It should be noted that the calibration and validation of the model has been done by manual calculations and solving equations based on conventional data.

In order to validate the models, an example was investigated as a sample by characteristic lines and finite difference method and the results of the models were compared with it. The following the examples and the results will be investigated.

\section{Validation}

It is considered a pipeline whit a tank at one end and a valve at the other end shows in Figure 1. The valve is closed in $3.5 \mathrm{sec}$ that causes an unsteady flow. The initial condition of the model has been showed in table 1. And the results are shown in tables 2 to 4 . As can be seen from the results (table 2 to table 4 ), both models are completely correct and allowable. So we can accept their performances in analysing the examples.

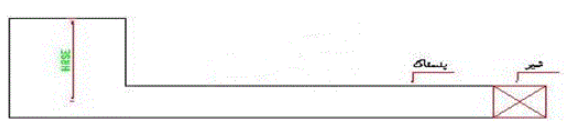

Figure 1. View of the validation example system.

Table 1. Initial condition of the validation model.

\begin{tabular}{lc}
\hline Parameter & Value \\
\hline $\mathrm{V}(\mathrm{m} / \mathrm{s})$ & 6 \\
$\mathrm{Q}(\mathrm{cms})$ & 2.62 \\
$\Delta \mathrm{H}(\mathrm{m})$ & 51 \\
$\mathrm{D}(\mathrm{mm})$ & 746 \\
$\mathrm{e}(\mathrm{mm})$ & 7.92 \\
$\mathrm{a}(\mathrm{m} / \mathrm{s})$ & 1086 \\
$\mathrm{tc}(\mathrm{s})$ & 3.5 \\
$2 \mathrm{~L} / \mathrm{a}(\mathrm{s})$ & 1.84 \\
$\mathrm{f}$ & 0.02 \\
$\Delta \mathrm{h}(\mathrm{m})$ & 49.35 \\
Duration $(\mathrm{s})$ & 20 \\
\hline
\end{tabular}

Table 2. Maximum and minimum pressure in pipeline.

\begin{tabular}{ccc}
\hline Max. pressure (m) & Min. pressure (m) & Leng. Pipe (m) \\
\hline 51 & 51 & 0 \\
86 & 16 & 100 \\
121 & 11 & 200 \\
155 & 6 & 300 \\
188 & 2 & 400 \\
221 & -1 & 500 \\
252 & -4 & 600 \\
283 & -7 & 700 \\
313 & -8 & 800 \\
342 & -9 & 900 \\
370 & -10 & 1000 \\
\hline
\end{tabular}

Table 3. Maximum and minimum pressure in pipeline Hammer model (characteristic line method.

\begin{tabular}{ccc}
\hline Max. pressure (m) & $\begin{array}{c}\text { Min. pressure } \\
(\mathbf{m})\end{array}$ & Leng. Pipe (m) \\
\hline 51 & 51 & 0 \\
86 & 16 & 100 \\
121 & 11 & 200 \\
155 & 6 & 300 \\
188 & 2 & 400 \\
221 & -1 & 500 \\
253 & -3.8 & 600 \\
284 & -6 & 700 \\
314 & -7.5 & 800 \\
343 & -8.4 & 900 \\
372 & -8.6 & 1000 \\
\hline
\end{tabular}

Table 4. Maximum and minimum pressure in pipeline Mike.net model (implicit finite difference method).

\begin{tabular}{ccc}
\hline Max. pressure (m) & $\begin{array}{c}\text { Min. pressure } \\
(\mathbf{m})\end{array}$ & Leng. Pipe (m) \\
\hline 51 & 51 & 0 \\
83 & 13 & 100 \\
118 & 9 & 200 \\
153 & 4 & 300 \\
185 & 2 & 400 \\
220 & -2 & 500 \\
250 & -5 & 600 \\
282 & -7 & 700 \\
310 & -7.5 & 800 \\
341 & -9 & 900 \\
368 & -11 & 1000 \\
\hline
\end{tabular}


First state: the power plant with a water pipe

A system consisting of a tank with a fixed head 140 (m) upstream, water pipe made from reinforced concrete with diameter of $2.7(\mathrm{~m})$ and a length of $100(\mathrm{~m})$, a flow control valve at the downstream and a design flow rate of $40(\mathrm{~m} 3 / \mathrm{s})$ (table 5). The unsteady flow is analysed for more than (2L/a) due to close the control valve. After extracting the initial and boundary conditions of the first state, the hydraulic instability is investigated using two numerical methods. Table 7 and table 8 show the absolute changes in pressure and velocity by the characteristic line and implicit finite difference methods.

Figure 2 shows the comparison changes of maximum pressure between two methods. According to the correlation coefficient between the two methods equal to $\mathrm{R} 2=95 \%$ it can be seen there is no significant difference (Figure 2).

Table 6. Initial and boundary condition of the first state.

\begin{tabular}{cc}
\hline Parameter & Value \\
\hline 7 & $\mathrm{~V}(\mathrm{~m} / \mathrm{s})$ \\
40 & $\mathrm{Q}(\mathrm{cms})$ \\
140 & $\Delta \mathrm{H}(\mathrm{m})$ \\
2700 & $\mathrm{D}(\mathrm{mm})$ \\
11 & $\mathrm{e}(\mathrm{mm})$ \\
1092 & $\mathrm{a}(\mathrm{m} / \mathrm{s})$ \\
10 & $\mathrm{tc}(\mathrm{s})$ \\
0.18 & $2 \mathrm{~L} / \mathrm{a}(\mathrm{s})$ \\
0.013 & $\mathrm{f}$ \\
1.18 & $\Delta \mathrm{h}(\mathrm{m})$ \\
20 & Duration $(\mathrm{s})$
\end{tabular}

Table 7. Absolute changes of pressure and velocity by the characteristic line method

\begin{tabular}{lc}
\hline Parameter & Value \\
\hline Max pressure $(\mathrm{m})$ & 147.34 \\
Min pressure $(\mathrm{m})$ & 132.65 \\
Max velocity $(\mathrm{m} / \mathrm{s})$ & 7 \\
Min velocity $(\mathrm{m} / \mathrm{s})$ & 0 \\
\hline
\end{tabular}

Table 8. Absolute changes of pressure and velocity by the implicit finite difference method

\begin{tabular}{lc}
\hline Parameter & Value \\
\hline Max pressure (m) & 147.13 \\
Min pressure (m) & 140 \\
Max velocity (m/s) & 7 \\
Min velocity (m/s) & 0 \\
\hline
\end{tabular}

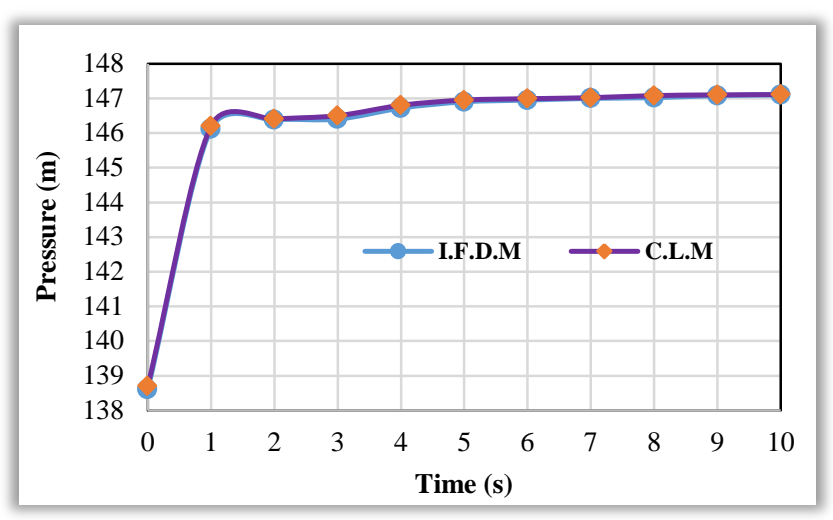

Figure 2. Comparison of changes in maximum pressure to time

\section{Second state: the power plant with three water pipes}

A system consisting of a tank with a fixed head 140 (m) upstream, water pipe made from reinforced concrete with diameter of $4.4(\mathrm{~m})$ and a length of $100(\mathrm{~m})$, water pipe made of reinforced concrete with three branches, each of which leads to a turbine with $2(\mathrm{~m})$ in diameters and $50(\mathrm{~m})$ in length, flow control valve at the end every water pipe and a design flow rate of $60(\mathrm{~m} 3 / \mathrm{s})$. The unsteady flow is analysed for more than $(2 \mathrm{~L} / \mathrm{a})$ due to close the control valve. Tables 9 and 10 show the absolute changes in pressure and velocity by the characteristic line and implicit finite difference methods.

Table 9. Absolute changes of pressure and velocity by the characteristic line method

\begin{tabular}{lc}
\hline Parameter & Value \\
\hline Max pressure $(\mathrm{m})$ & 145.03 \\
Min pressure $(\mathrm{m})$ & 137.412 \\
Max velocity $(\mathrm{m} / \mathrm{s})$ & 7 \\
Min velocity $(\mathrm{m} / \mathrm{s})$ & 0 \\
\hline
\end{tabular}

Table 10. Absolute changes of pressure and velocity by the implicit finite difference method

\begin{tabular}{lc}
\hline Parameter & Value \\
\hline Max pressure $(\mathrm{m})$ & 144.85 \\
Min pressure $(\mathrm{m})$ & 139.86 \\
Max velocity $(\mathrm{m} / \mathrm{s})$ & 7 \\
Min velocity $(\mathrm{m} / \mathrm{s})$ & 0 \\
\hline
\end{tabular}

Figure 3 shows the comparison changes of maximum pressure between two methods at the boundary of transmission and water pipe. According to the correlation coefficient between the two methods equal to $\mathrm{R} 2=91 \%$ it can be seen there is no significant difference. 


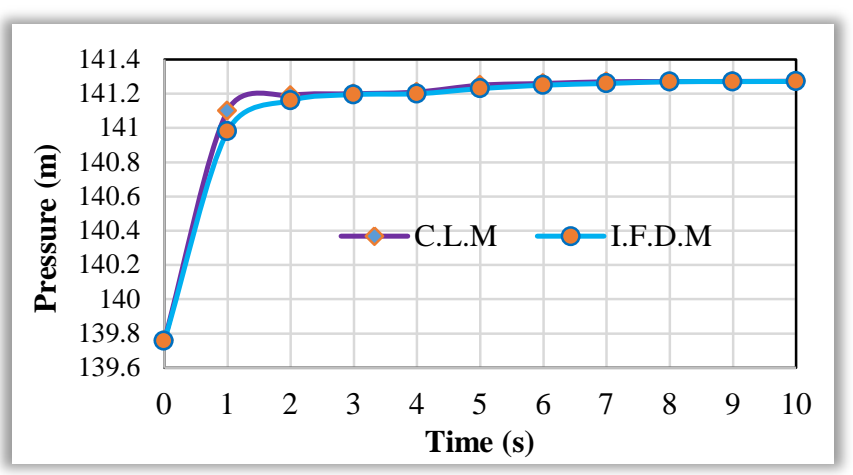

Figure 3. Comparison of changes in maximum pressure to time at the boundary of transmission and water

Third state: investigation of the C.F.L condition

In this state we investigate the sensitivity of the methods to the Courant-Friedrichs-Levy (C.F.L)stability condition. For this purpose, we used model in initial state. Table 11 and figure 4 show the maximum pressure changes to the C.F.L condition in characteristic line method. According to the table 11 and figure 4 in can be seen that the maximum pressure increases by increasing the C.F.L. In table 12 and figure 5 changes of the maximum pressure to the C.F.L condition have been shown at the implicit finite difference method. In figure 6 the maximum pressure changes in two methods to the C.F.L has been compered.

Table 11. Maximum pressure changes to the C.F.L condition at the characteristic lines method

\begin{tabular}{cc}
\hline C.F.L & Max pressure \\
\hline 0.5 & 148 \\
0.7 & 147.7 \\
1 & 147.3 \\
2 & 155 \\
3 & 165 \\
4 & 175 \\
\hline
\end{tabular}

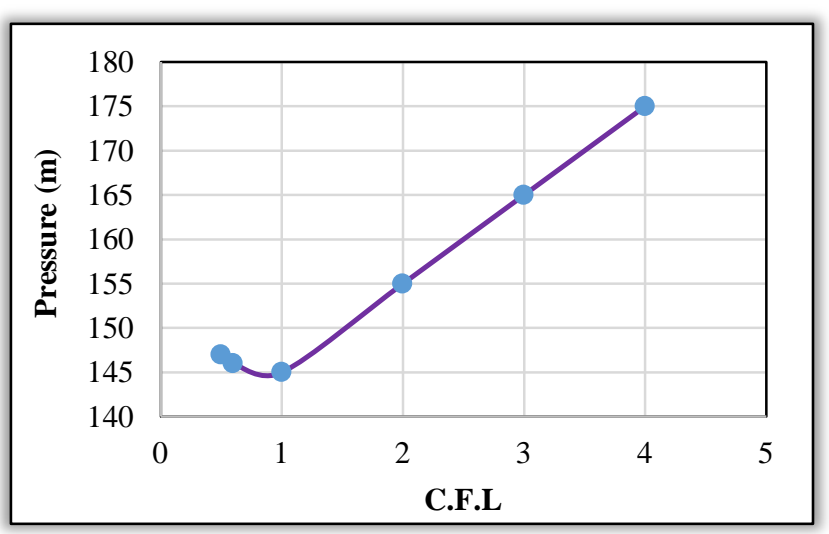

Figure 4. Maximum pressure changes to the C.F.L condition at the characteristic lines method.
Table 12. Maximum pressure changes to the C.F.L condition at the implicit finite difference method

\begin{tabular}{cc}
\hline C.F.L & Max pressure \\
\hline 0.5 & 153 \\
0.7 & 147 \\
1 & 147 \\
2 & 147 \\
3 & 147.5 \\
4 & 148 \\
\hline
\end{tabular}

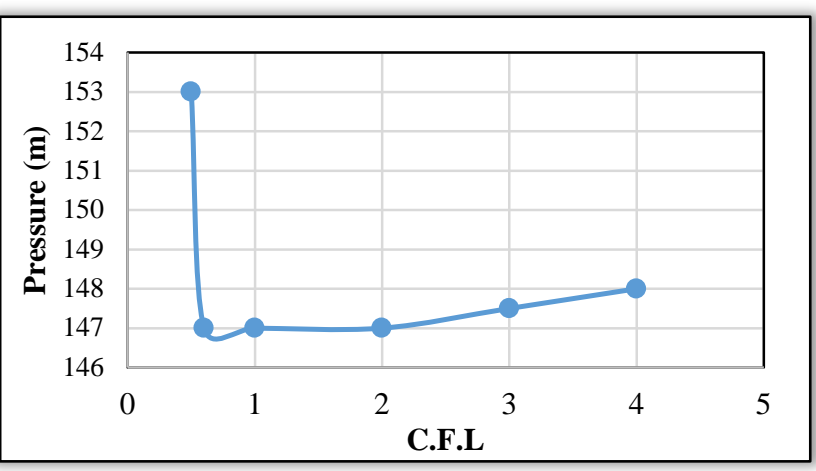

Figure 5. Maximum pressure changes to the C.F.L condition at the implicit finite difference method

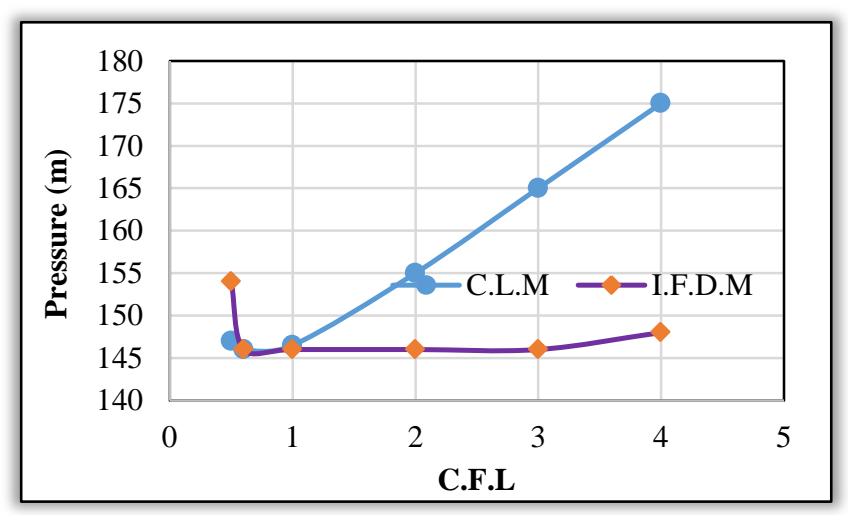

Figure 6. Maximum pressure changes to the C.F.L condition at the two methods.

\section{Fourth State: effect of the Darcy-Weisbach coefficient (f):}

According to the importance of the Darcy - Weisbach roughness coefficient (f) in damping of the unsteady flows, in this state we investigated the effect of $f$ changes to the governing equations at each time steps. For this reason, used the first state to investigation. Table 13 and figure 7 show the $f$ changes to time. According to the table 13 and figure 7 it is obvious that the $f$ changes is in proportion to the system mass changes which it directly effects on the minimum and maximum flow characteristics and is the main factor of damping. 
Table 13. The $f$ changes to the simulation time.

\begin{tabular}{cc}
\hline Time $(\mathbf{s})$ & $\mathbf{f}$ \\
\hline 0 & 0.013 \\
1 & 0.013 \\
2 & 0.013 \\
3 & 0.013 \\
4 & 0.013 \\
5 & 0.013 \\
6 & 0.013 \\
7 & 0.013 \\
8 & 0.013 \\
9 & 0.013 \\
10 & 0.023 \\
11 & 0.015 \\
12 & 0.023 \\
13 & 0.016 \\
14 & 0.018 \\
15 & 0.016 \\
16 & 0.017 \\
17 & 0.017 \\
18 & 0.016 \\
19 & 0.018 \\
20 & 0.015 \\
\hline
\end{tabular}

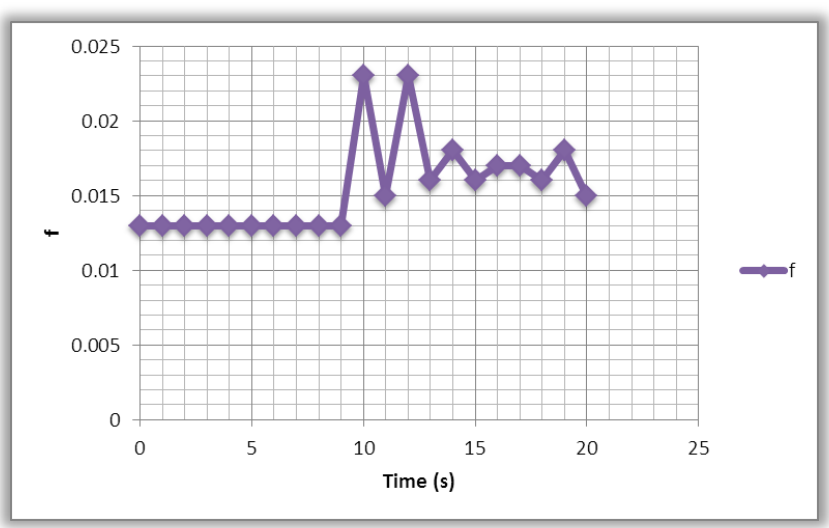

Figure 7. The $f$ changes to the simulation time.

\section{CONCLUSION}

In this study, due to the importance of hydraulic instability in hydropower plants and various methods in the field of analysis of these instabilities, we used the two numerical methods of characteristic lines and the implicit finite difference with Verwy \& Yu scheme, which is widely used in instability analysis and their advantages and disadvantaged determined. For this purpose, at first the system initial conditions were exported by stable hydraulic flow analysis software (Epanet). Then implemented separately in Hammer computer models (with numerical method of characteristic lines) and MIKE.net (with implicit finite difference numerical method). Then, the results of hydraulic instability analysis under the same boundary conditions were evaluated.

After compression between two methods of the characteristics line and the implicit finite difference it showed that the characteristics line

Method is very efficiency and stability in solving problems. Also, according to the results it was showed that the maximum and minimum pressure calculated by the characteristic line method is less than the implicit finite difference method. In the characteristic method, perturbations and fast wave fronts are presented with more accuracy than the implicit finite difference method. At points near the upstream, downstream and middle boundaries, the accuracy of the characteristic method in presenting pressure and flow fluctuations is higher than the implicit finite difference method. Given that the characteristic method is explicitly solved, so the stability condition (C.F.L $\leq 1$ ) must always be satisfied. However, it was expected that in the implicit finite difference method, this condition would not need to be met as explicitly as the explicit method, so that larger time steps $\Delta t$ could be chosen. But the results showed that the stability condition must be approximately equal to 1 (C.F.L $\approx 1$ ) in the implicit method because otherwise the oscillations will be produced with high frequency near the sharp front of the waves, which are not real and have no physical justification.

In the characteristic line method, it is recommended not to use specific time steps and avoid from interpolation by choosing the appropriate $\Delta \mathrm{t}$ because it decreases the wave front.

The results of $\mathrm{f}$ changes in the both methods show that is not correct to take constant value for the $f$ and it must be calculated according to the velocity changes at different times.

\section{Conflict of interest}

There is no any conflict of interest whatsoever with any third party.

\section{REFERENCE}

Bergant A, Ross Simpson A, Vìtkovsk J. (2001). Developments in unsteady pipe flow friction modelling. Journal of Hydraulic Research. 39(3):249-57. Google Scholar, https://doi.org/10.1080/00221680109499828

Brunone B, Golia UM, Greco M. (1991). Some remarks on the momentum equation for fast transients. InProceedings of the International Meeting on Hydraulic Transients with Column Separation Sep 4 (pp. 201-209). Google Scholar 
Chudhury M.H and Hussaini M.Y (1985). Second-order accurate explicit finite-difference schemes for water hammer analysis. Journal of fluid Eng. Vol. 107. pp. 523-529. Google Scholar, https://doi.org/10.1115/1.3242524

Driels MR. (1975). Predicting optimum two-stage valve closure. ASME paper. Nov 30. Google Scholar

Ghidaoui MS, Kolyshkin AA. (2001). Stability analysis of velocity profiles in water-hammer flows. Journal of Hydraulic Engineering. 127(6): 499-512. Google Scholar, https://doi.org/10.1061/(ASCE)0733-9429(2001)127:6(499)

Ghidaoui MS, Mansour SG, Zhao M. (2002). Applicability of quasisteady and axisymmetric turbulence models in water hammer. Journal of Hydraulic Engineering. 128(10): 91724. Google Scholar, https://doi.org/10.1061/(ASCE)07339429(2002)128:10(917)

Hou Q, Kruisbrink AC, Tijsseling AS, Keramat A. (2012). Simulating water hammer with corrective smoothed particle method. Eindhoven University of Technology. May. Google Scholar

Chaudhry MH. (1979). Applied hydraulic transients. Google $\underline{\text { Scholar }}$

Kwon HJ, Lee JJ. (2008). Computer and experimental models of transient flow in a pipe involving backflow preventers. Journal of Hydraulic Engineering. 134(4):426-34. Google
Scholar, $\quad$ https://doi.org/10.1061/(ASCE)07339429(2008)134:4(426)

Saikia MD, Sarma AK. (2006). Simulation of water hammer flows with unsteady friction factor. ARPN Journal of Engineering and Applied Sciences. 1(4): 35-40. Google $\underline{\text { Scholar }}$

Shimada M, Okushima S. (1984). New numerical model and technique for waterhammer. Journal of Hydraulic Engineering. 110(6): 736-48. Google Scholar, https://doi.org/10.1061/(ASCE)0733-9429(1984)110:6(736)

Tijsseling AS, Bergant A. (2007). Meshless computation of water hammer. Department of mathematics and computer science, University of technology Oct 24.Google Scholar

Zhao M, Ghidaoui MS. (2003). Efficient quasi-two-dimensional model for water hammer problems. Journal of Hydraulic Engineering. 129(12): 1007-13. Google Scholar, https://doi.org/10.1061/(ASCE)0733-9429(2003)129:12(1007)

Zhao M, Ghidaoui MS. (2004). Godunov-type solutions for water hammer flows. Journal of Hydraulic Engineering. 130(4): 341-8. Google Scholar, https://doi.org/10.1061/(ASCE)0733-9429(2004)130:4(341)

Zielke W (1968). Frequency -dependent Friction in Transient pipe flow. Journal of Basic Eng., ASME. 90(9): 109-115. Google Scholar, https://doi.org/10.1115/1.3605049 